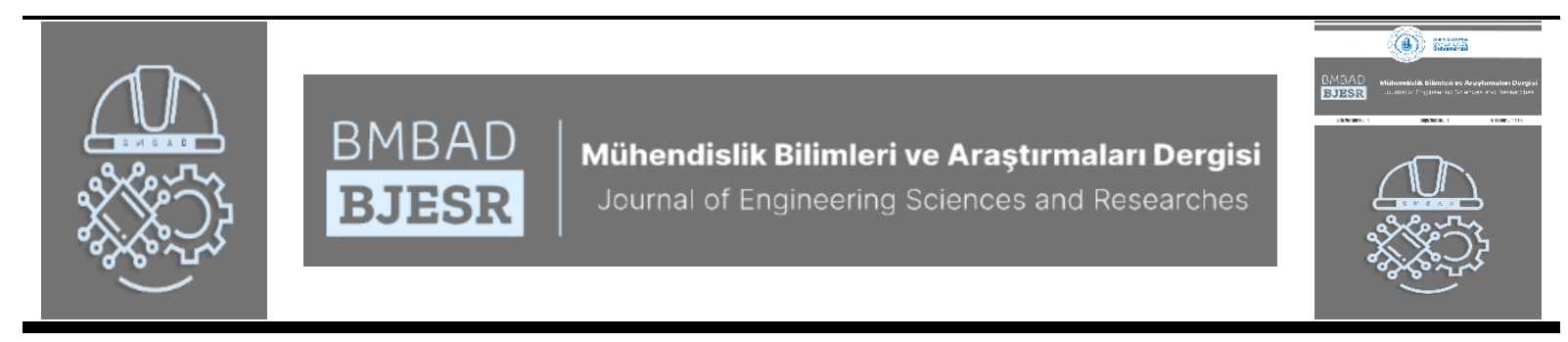

\title{
Elektrik Güç Sistemleri için Kontrollü Kesici Tasarımı
}

\section{Controlled Breaker Desing for Electric Power Systems}

\author{
${ }^{1}$ İsmail BOZDA $\breve{G}$ (D) ${ }^{2}$ Serhat Berat EFE \\ ${ }^{I}$ Bandırma Onyedi Eylül Üniversitesi, Fen Bilimleri Enstitüsü, Bandırma/Balıkesir, Türkiye \\ ${ }^{2}$ Bandırma Onyedi Eylül Üniversitesi, Mühendislik ve Doğa Bilimleri Fakültesi, Bandırma/Balıkesir, Türkiye
}

${ }^{1}$ ismailbozdag@ogr.bandirma.edu.tr, ${ }^{2}$ sefe@bandirma.edu.tr

Araştırma Makalesi/Research Article

A R T I C LE IN F O

Article history

Received : 17 August 2021

Accepted : 15 September 2021

Keywords:

Fault analysis, High voltage breakers, Electric power systems.

\section{A B S T R A C T}

While designing modern power systems, it is aimed to keep the cost items first and then the malfunctions that may occur on the relevant system at minimum levels. There are overhead lines with radial and individual outlets among the distribution networks built. About lines, frequent breakdowns occur due to bird strikes, insulator breakdowns, humidity, etc. In this study, it is aimed to examine the effects of faults experienced at different points of a power system and to dampen these faults with the designed controlled breaker without affecting different points of the system. In the study, it was observed that the rated current, which was at the level of $54 \mathrm{~A}$, increased to $1.5 \mathrm{kA}$ with the fault. The application is of great importance in terms of increasing equipment life in transmission and distribution networks and isolating fault zones for only 0.001 seconds in a power system with more than one supply point.
M A K A L E B İ L G İ S İ

Makale Tarihleri

Gönderim : 17 Ağustos 2021

Kabul : 15 Eylül 2021

\section{Anahtar Kelimeler:}

Arıza analizi, Yüksek gerilim kesicileri, Elektrik güç sistemleri.

\section{Ö Z E T}

Günümüzde güç sistemlerinin tasarımı yapılırken ilk olarak maliyet kalemlerinin, daha sonra ise ilgili sistem üzerinde yaşanabilecek arızaların minimum seviyelerde tutulması hedeflenmektedir. Geçmiş yıllarda yapılan ve günümüzde de halen işletilen dağıtım şebekeleri içerisinde radyal ve müstakil çıkışları barındıran birden fazla havai hatlar mevcuttur. Söz konusu hatlar üzerinde ise kuş çarpmaları, izolatör arızaları, nem vb. nedenlerden dolayı sıkça arızalar meydana gelmektedir. Bu çalışmada, bir güç sisteminin farklı noktalarında yaşanan arızaların etkilerinin incelenmesi ve bu arızaların, sistemin farklı noktalarına etki etmeden tasarlanan kontrollü kesici ile sönümlendirilmesi amaçlanmıştır. Çalışmada 54 A seviyelerinde olan nominal akım arıza ile birlikte $1.5 \mathrm{kA}$ seviyelerine çıktığı gözlemlenmiştir. Uygulama, iletim ve dağıtım şebekelerinde teçhizat ömürlerinin artması ve birden fazla besleme noktası olan bir güç sistemi içerisinde arıza bölgelerinin sadece 0,001 saniye süre ile izole edilmesi açısından büyük önem arz etmektedir. 


\section{GİRIŞ}

Güç sistemleri, enerjinin sürekli ve kararlı halde tutulması gereken ve bir işin sürdürülebilirliğini sağlayan en önemli yapılardan birisidir. Bu özelliği gereği hayati öneme sahip bu sistemlerin kusursuz biçimde kontrolü de büyük önem arz etmektedir. Bu nedenle sözkonusu sistemler sürekli izlenmeli ve gerekli durumlarda en kısa sürede müdahale sağlanmalıdır [1], [2]. Bir güç sistemi içerisinde havai hatların fazlalığı arıza noktalarını da beraberinde getirmektedir. Güç sistemi içerisinde geçici kararsızlık durumlarının yaşanması, elektrik şebekesinde ekonomik kayıplara neden olan ana maddelerden biridir [3], [4]. Yaşanabilecek asimetrik arızaların sönümlendirilmesi için ise çeşitli kontrol yapıları ile birlikte kumanda edilen yüksek gerilim kesicileri kullanılmaktadır.

Literatürde bulunan yüksek gerilim kesicileri ile ilgili yayınların dağılımı incelendiğinde iki temel alanda çalışmaların olduğu görülmektedir. Bu alanlardan birincisi kesicilerin yapısal tasarımı ve çalışma koşullarının iyileştirilmesi, bu çalışmanın da içerisinde bulunduğu ikincisi ise kesicilerin kontrolüdür. Bu çalışmaların öne çıkanlarından birinde yüksek gerilim kesicilerinin ayarlanması ve kontrolü, tasarlanan yapay sinir ağı algoritmalı ve PLC (Programmable Logic Controller - Programlanabilir Mantıksal Denetleyici) tabanlı bir kontrolör ile yapılmıştır [5]. Bir başka çalışmada, otomatik kapanan kesicilerin dağıtım şebekesi üzerindeki etkileri incelenmiş ve kesici kontrolünün özellikle kararlı çalışma açısından önemi vurgulanmışıır [6]. Kesicilerin akıllı şebeke uygulamalarında ne kadar önemli olduğu [7] çalışmasında irdelenmiştir. Bu çalışmada, mevcut ve gelecekteki sistemlerde kullanılacak kesiciler ile ilgili detaylı bir analiz yapılmış, güç sistemindeki gerilim, akım ve reaktif güç akışının iyileştirilmesi amaçlanmıştır. Literatürde uygulamalı çalışmalar da mevcuttur. Araştırmacılar, bir veri toplama kartı üzerinden elde ettikleri veriler aracılığı ile bilgisayar temelli bir kesici kontrolü uygulaması gerçekleştirmiş̧ir. LabVIEW (Laboratory Virtual Instrument Engineering Workbench) yazılımı kullanılarak yapılan bu çalışmanın sonuçları, önerilen modelin kesiciyi kusursuz biçimde kontrol edebildiğini göstermiş̧tir [8]. Benzer şekilde bir başka çalışmada yine kesici, nesnelerin interneti (IoT) yaklaşımı ile kontrol edilmiştir [9]. Literatürdeki çalışmalar, kesici kontrolünün sistem kararlılı̆̆ı ve güvenliği açısından ne kadar önemli olduğunu ortaya çıkarmıştır. Bu çalışmanın temel motivasyonunu bu yaklaşım oluşturmuştur.

Bu kapsamda, öncelikle gerçek bir güç sisteminin MATLAB/Simulink platformunda modellemesi yapılmıştır. Modellemenin herhangi bir noktasında faz-toprak, faz-faz ve simetrik üç faz arızalarından biri yaşandığında, kesici ile ilgili arızanın farklı bölgelere sıçramadan en kısa sürede sönümlendirilmesi hedeflenmiştir. Bu çalışma için tasarlanan kesici devre bloğu temelinde lojik devre (0-1) mantığı bulunmaktadır. Okunan nominal akım değeri ile belirlenen üst sınır akım değeri karşılaştııılarak bir sayıcı (counter) bloğu üzerinden kesiciye açma sinyali (lojik 1) gönderilmektedir. Elde edilen sonuçlar sistemin çeşitli noktalarından alınan grafikler üzerinde tartışılmış ve çalışmanın performansı değerlendirilmiştir.

\section{GÜÇ SİSTEMLERINDE ARIZALAR}

Güç sistemlerinde kararlı çalışma devam eder iken, bu kararlılığı bozacak bir takım beklenmedik olaylar yaşanabilmektedir. Bu beklenmedik durumlar genellikle iletim ve dağıtım hatlarında yaşanan kısa devre olaylarıdır. Kısa devre olan iletim veya dağıtım hattında akım artışına karşılık yüksek güç talebi doğacaktır. Mekanik gücünde sınırlı oluşu ile bu güç talebi karşılanamayacağından sistemde kararsızlık durumu oluşacaktır. Bu kısa devre arızasının uzun bir süre devam etmesi durumunda ise güç sisteminde büyük çaplı hasarlar meydana gelebilmektedir. Güç sistemlerinde meydana gelen kısa devre arızalarından sistem üzerinde etkileri en fazla olanı üç faz toprak simetrik kısa devre arızasıdır. Bu arızaların yanında iki faz-toprak, tek-faz toprak ve fazfaz arızaları da meydana gelebilmektedir [10].

\subsection{Bir Faz - Toprak Arızası}

Bir fazın toprağa doğrudan veya bir empedans üzerinden teması ile oluşan arıza çeşididir. Özellikle açık şebekelerde \%80'lik oluşma sıklığı bulunmaktadır. Oluşan arıza akımı arıza noktasına da bağlı olarak en yüksek kısa devre akımı değerlerine sahip olabilmektedir. Arıza anında arıza akımı 10-100 kat artar iken diğer akım değerleri yaklaşı sıfır olmaktadır. Arıza akımının sıfır geçişlerinde ilgili arıza gerilimi maksimum olur iken, maksimum geçişlerde ise sıfir değerine düşmektedir. Bir faz-toprak arızasının a fazında gerçekleştiğini varsayıldığında matematiksel ifade;

$$
\begin{aligned}
& I_{0}=I_{1}=I_{2}=\frac{V_{F}}{Z_{0}+Z_{1}+Z_{2}+\left(3 Z_{F}\right)} \\
& I_{a}=I_{0}=I_{1}=I_{2}=3 I_{1}=\frac{V_{f}}{Z_{0}+Z_{1}+Z_{2}+\left(3 * Z_{F}\right)} \\
& I_{b}=\left(I_{0}+a^{2} I_{1}+a I_{2}\right)=0 \\
& I_{c}=\left(I_{0}+a I_{1}+a^{2} I_{2}\right)=0
\end{aligned}
$$




\subsection{Faz - Faz Arızası}

İki fazın birbiriyle teması sonucu oluşan arıza çeşididir. Bu tip arızanın matematiksel ifadesi aşağıda belirtilmiştir.

$I_{0}=0$

$I_{1}=-I_{2}=\frac{V_{F}}{Z_{0}+Z_{1}+Z_{2}}$

$I_{a}=I_{0}+I_{1}+I_{2}=0$

$I_{b}=\frac{-j \sqrt{3} V_{f}}{Z_{0}+Z_{1}+Z_{2}}$

$I_{c}=\left(I_{0}+a I_{1}+a^{2} I_{2}\right)=-I_{b}$

\section{3. İki Faz - Toprak Arızası}

İki fazın birbiriyle ve toprakla teması sonucu oluşan arıza çeşididir. Bu tip arızanın matematiksel ifadesi aşağıda belirtilmiştir.

$\mathrm{I}_{1}=\frac{\mathrm{V}_{\mathrm{F}}}{\mathrm{Z}_{1}+\left[\frac{\mathrm{Z}_{2}\left(\mathrm{z}_{0}+3 \mathrm{Z}_{\mathrm{F}}\right)}{\mathrm{Z}_{2}+\mathrm{Z}_{0}+3 \mathrm{Z}_{\mathrm{F}}}\right]}$

$\mathrm{I}_{2}=-\mathrm{I}_{1} \frac{\mathrm{Z}_{0}+3 \mathrm{Z}_{\mathrm{F}}}{\mathrm{Z}_{1}+\left[\frac{\mathrm{z}_{2}\left(\mathrm{z}_{0}+3 \mathrm{Z}_{\mathrm{F}}\right)}{\mathrm{Z}_{2}+\mathrm{Z}_{0}+3 \mathrm{Z}_{\mathrm{F}}}\right]}$

$\mathrm{I}_{0}=-\mathrm{I}_{1} \frac{\mathrm{Z}_{2}}{\mathrm{z}_{1}+\left[\frac{\mathrm{z}_{2}\left(\mathrm{z}_{0}+3 \mathrm{Z}_{\mathrm{F}}\right)}{\mathrm{z}_{2}+\mathrm{Z}_{0}+3 \mathrm{Z}_{\mathrm{F}}}\right]}$

\section{Simetrik Üç Faz Arızası}

Üç fazın birbiriyle teması sonucu oluşan arıza çeşididir. Bu arıza tipinde toprak teması olup olmamasının parametrelere herhangi bir etkisi yoktur. Bu tip arızanın matematiksel ifadesi aşağıda belirtilmiştir.

$I_{0}=0$

$I_{2}=0$

$I_{1}=\frac{V_{F}}{Z_{1}}$

\section{GÜÇ SİSTEMININ MODELLENMESİ}

Önceki bölümlerde belirtildiği üzere, elektrik güç sistemlerindeki arızaların etkilerinin belirlenmesi ve arıza sönümlendirmenin öneminin vurgulanması amacıyla, MATLAB/Simulink platformu altında, Şekil 1' de gösterilen güç sistemi tasarlanmıştır.

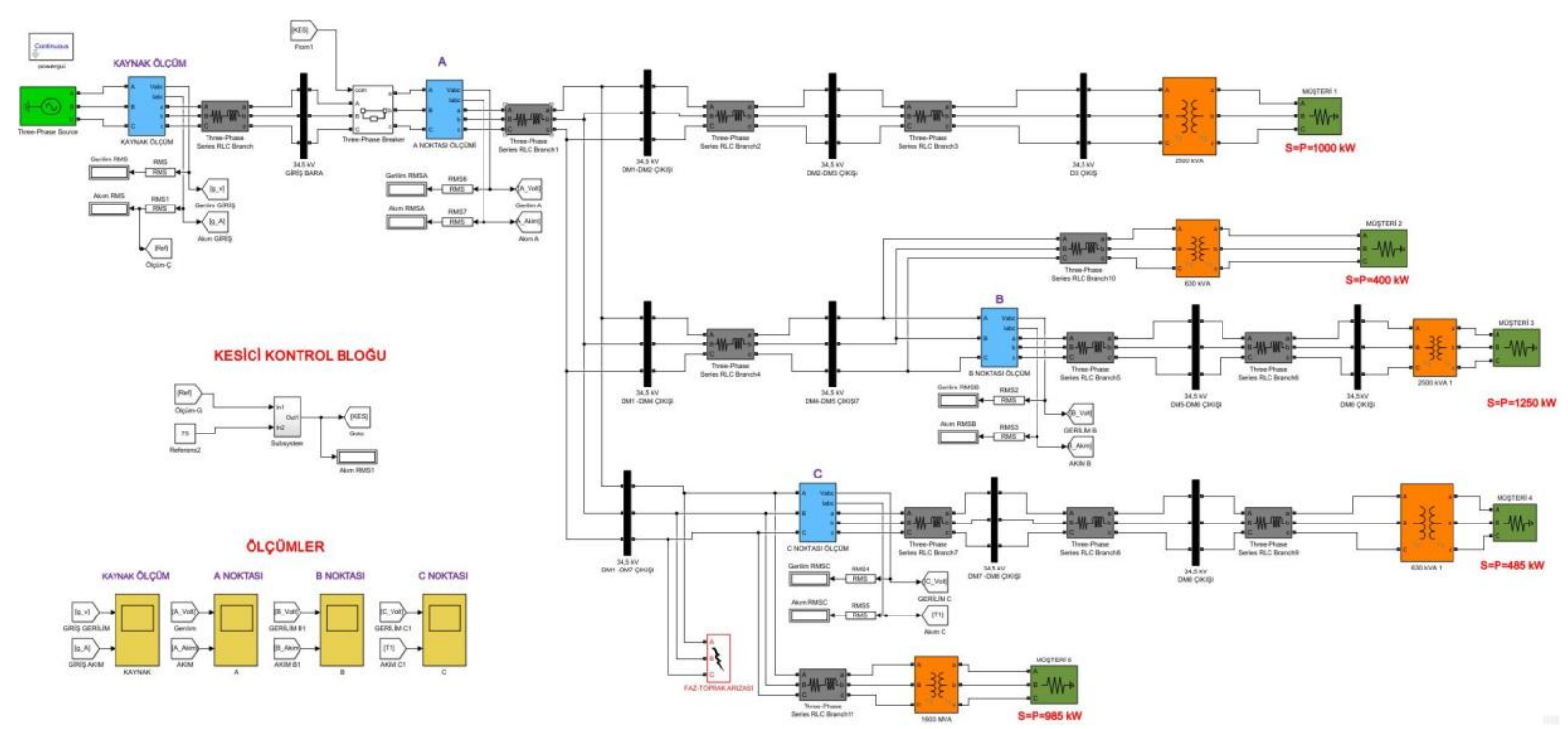

Şekil 1. Güç sistemi modeli 
Bu modelde 1 adet kaynak, 5 adet transformatör, 5 adet yük, 1 adet arıza kaynağı ile birlikte ölçüm blokları ve hatları belirten RL (direnç-bobin) blokları bulunmaktadır. Sistem içerisinde kaynak gerilimi 34,5 kV'tur. Müşteri trafoları faz-faz gerilim değerleri 34,5 kV / 0,4 kV (Primer / Sekonder)'tur. Aktif güç değerleri; birinci yük için $1000 \mathrm{~kW}$, ikinci yük için $400 \mathrm{~kW}$, üçüncü yük için $1250 \mathrm{~kW}$ ve dördüncü yük için $485 \mathrm{~kW}$ belirlenmiş olup, reaktif güçler dikkate alınmamıştır.

\subsection{Kesici Kontrolü Tasarımı}

Çalışmanın temel amacı kapsamında tasarlanan güç sistemi bir adet otomatik kesici içermektedir. Bu kesiciye ait kontrol bloğunun içyapısı Şekil 2'de gösterilmiştir.

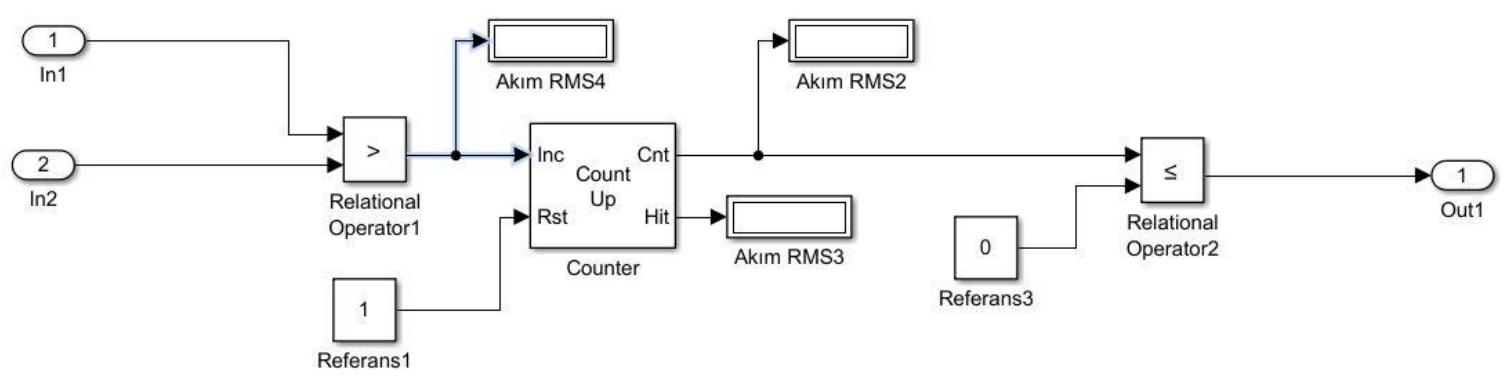

Şekil 2. Kesici kontrol bloğu iç yapısı

İletim veya dağıtım şebekelerinde yaşanan asimetrik arızalarda kesicilerin kontrolü çok büyük bir önem arz etmektedir [11], [12]. Kesici kontrolü sağlanamaması durumunda, arızanın etkisi ile şebeke içerisinde bulunan teçhizatlarda ciddi zararlar meydana gelebilir [13]. Arıza durumunda kesicilerinin kontrolü günümüz teknolojisi ile çeşitlilik kazanmış durumdadır. En sık kesici kontrol yapıları ise PLC (Programmable Logic Controller Programlanabilir Mantıksal Denetleyici) ve koruma röleleri ile yapılan kontrollerdir [5]. Güç sistemlerinde kullanılan kesici kontrol yapılarından bir diğeri ise tekrar kapama röleleridir [14]. Tasarlanan modellemede, arızanın yaşanması ile birlikte ayarlanan nominal değer üzerine çıkılacağından kesici açacaktır. Kesicinin kontrolü, koruma rölesi çalışma mantığı ile yapılmış olup, tekrar kapama işlemi tasarlanan SCADA (Supervisory Control and Data Acquisition- Merkezi Denetleme Kontrol ve Veri Toplama) ekranı üzerinden kontrollü olarak operatöre yaptırılmaktır.

\subsection{Grafiksel Kullanıcı Arayüzü Tasarımı}

$\mathrm{Bu}$ kontrol bloğu, tasarlanan bir GUI (Graphical User Interface - Grafiksel kullanıcı arayüzü) üzerinden denetlenmektedir. İlgili arayüz ekranı Şekil 3 'te verilmiştir.

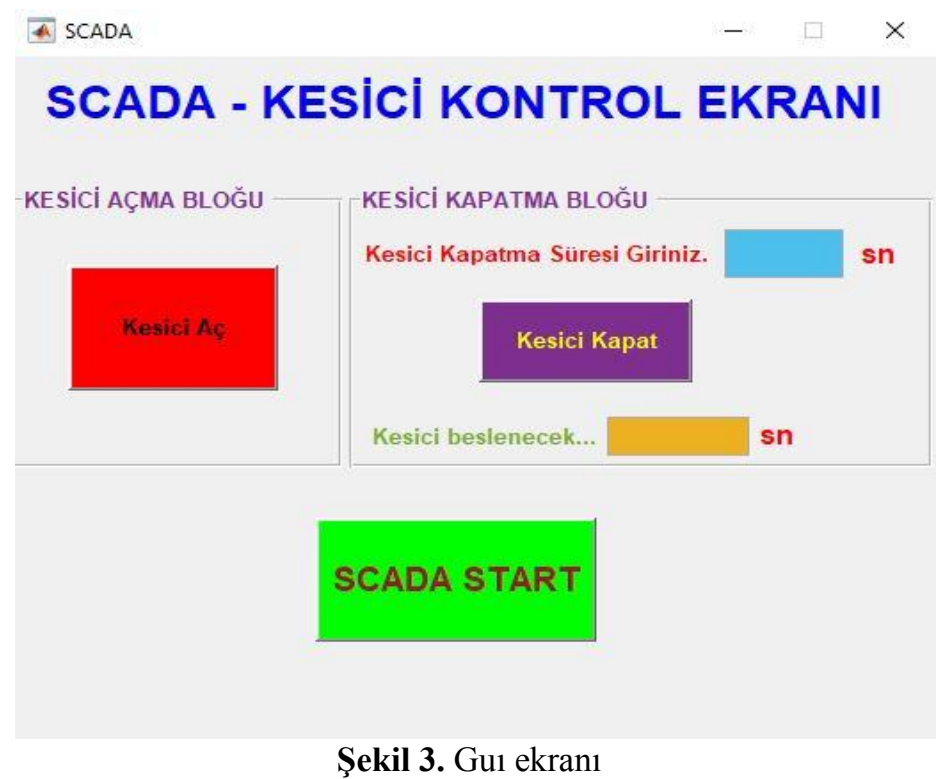


Kontrol ekranında üç adet buton ve iki adet zaman sayacı bulunmaktadır. SCADA (Supervisory Control and Data Acquisition- Merkezi Denetleme Kontrol ve Veri Toplama) ekranı üzerinde "SCADA Start" butonu benzetimin başlamasını, "Kesici Aç" butonu kesiciye aç komutu (Lojik 1) göndererek kesicinin operatör tarafından kontrollü şekilde açılmasını, "Kesici Kapat” butonu ise girilen "kesici Kapatma Süresi” sonunda, operatör tarafından kesicinin kontrollü kapatılması işlemleri gerçekleştirilir. Kesiciye kapatma komutu verildikten sonra ise kesicinin kapanacağı zaman diliminin geri sayımı "Kesici Beslenecek" zaman sayıcısı tarafından operatöre gösterilmektedir.

\section{SISTEMIN ANALIZI}

Çalışmanın temel amacı gereği, tasarlanan güç sisteminin çeşitli çalışma koşulları için senaryolar belirlenerek analizi yapılmış ve bu analiz sonuçları irdelenmiştir. Bu kapsamda, 30 saniye süreli benzetimin 4-5 saniye aralığında sırasıyla faz- toprak arızası, faz-faz arızası ve simetrik üç faz arızası meydana gelmiştir. Söz konusu arızaların kesici bloğu devrede ve devre dışı olduğu koşullar göz önüne alınarak; A ölçüm bloğunda akım ve gerilimde meydana gelen değişiklikler gözlenmiştir.

\subsection{Senaryo 1: Bir Faz - Toprak Arızası Durumu}

Tasarlanan sistemin performansının değerlendirilmesi amacı ile uygulanan senaryolardan birincisi bir faz toprak arızasıdır. Bu senaryoda bir fazın toprak teması halinde sistemin akım ve gerilim karakteristikleri A ölçüm bloğu üzerinden alınmış olup Şekil 4'te verilmiştir.

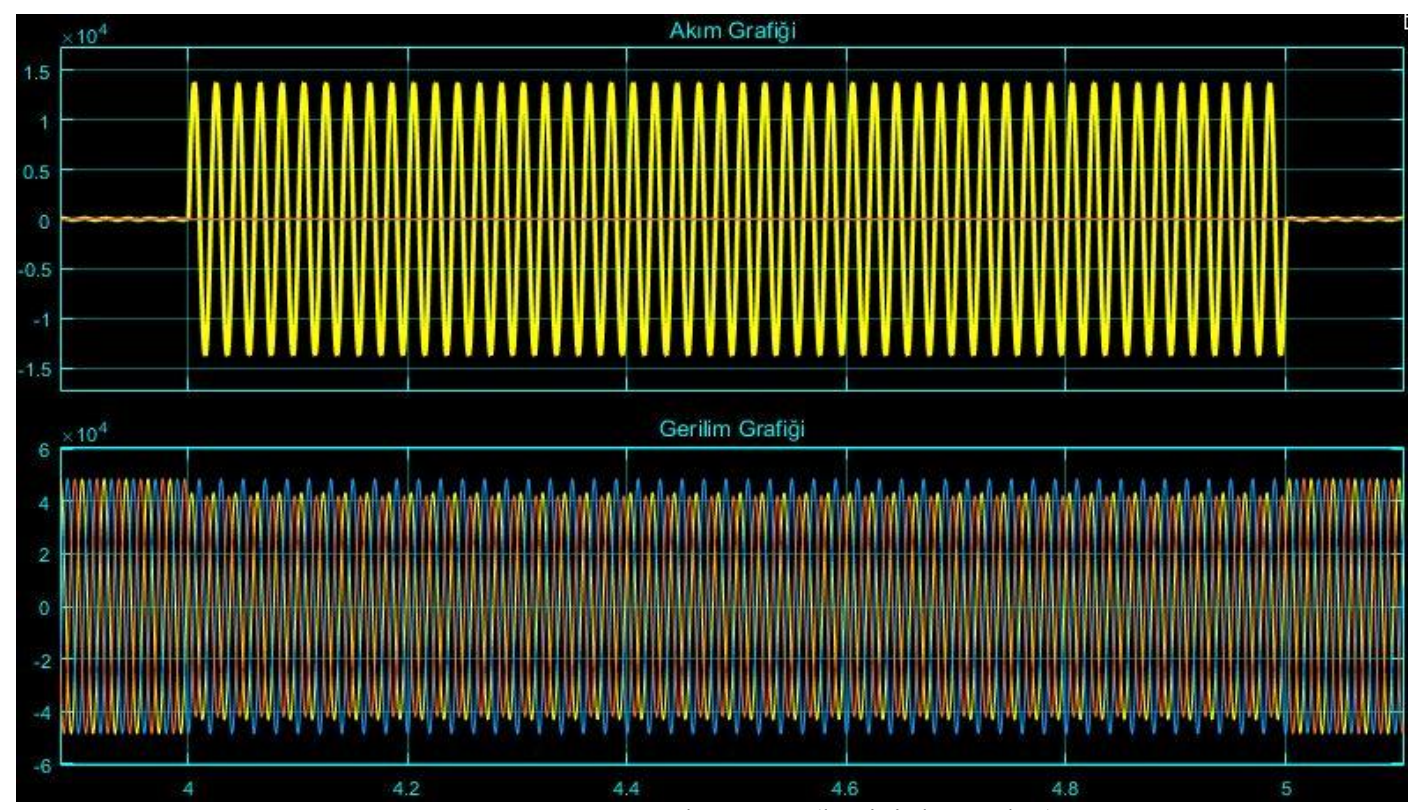

Şekil 4. Bir faz - toprak arızası (kesici devre dışı)

Kesici devre dışı iken sistem üzerinde bir faz - toprak arızası meydana geldiğinde, devre elemanları üzerinden nominal yük akımı olan 54 A seviyelerinde akım akmakta iken, arızanın meydana gelmesi ile arıza süresi boyunca yaklaşık $1.5 \mathrm{kA}$ (nominal akımın 28 katı) seviyelerinde arıza akımı geçtiği görülmektedir. Ayrıca A ve B faz gerilimlerinde de birtakım bozukluklar meydana geldiği Şekil 5 üzerinde açıkça gözlemlenebilmektedir. 


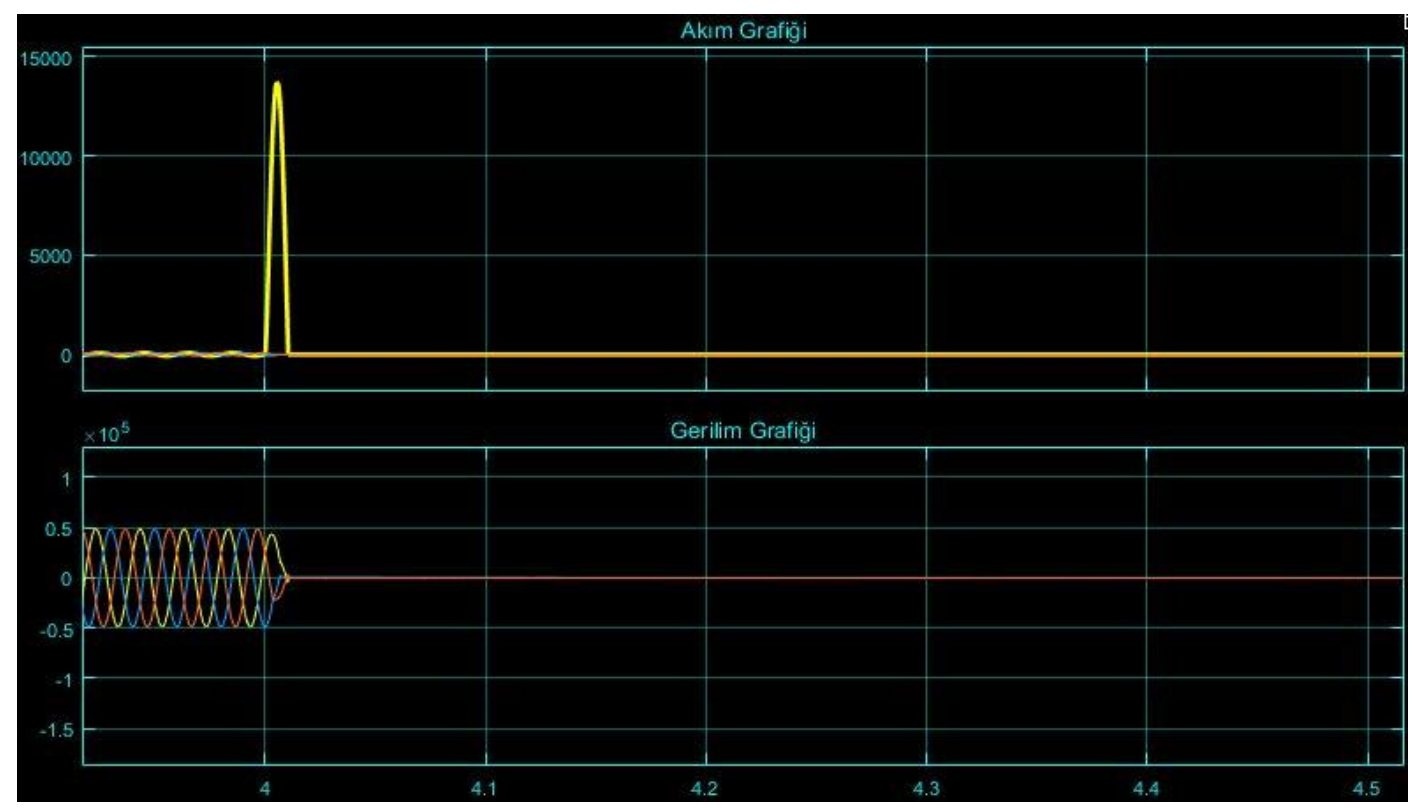

Şekil 5. Bir faz - toprak arızası (kesici devrede)

Bir faz - toprak arızası meydana geldiğinde kesicinin devrede olduğu senaryoda, nominal akım değeri set edilen açma akımı üzerine çıktığı anda kesici devreye girmektedir (Enerji kesilmektedir). Böylelikle devre elemanları yüksek akım ve dengesiz gerilimlere maruz bırakılmamaktadır.

\subsection{Senaryo 2: Faz - Faz Arızası}

Tasarlanan sistemin performansının değerlendirilmesi amacı ile uygulanan senaryolardan ikincisi faz faz arızasıdır. Bu senaryoda iki fazın birbiri ile teması halinde sistemin akım ve gerilim karakteristikleri A ölçüm bloğu üzerinden alınmış olup Şekil 6'da verilmiştir.

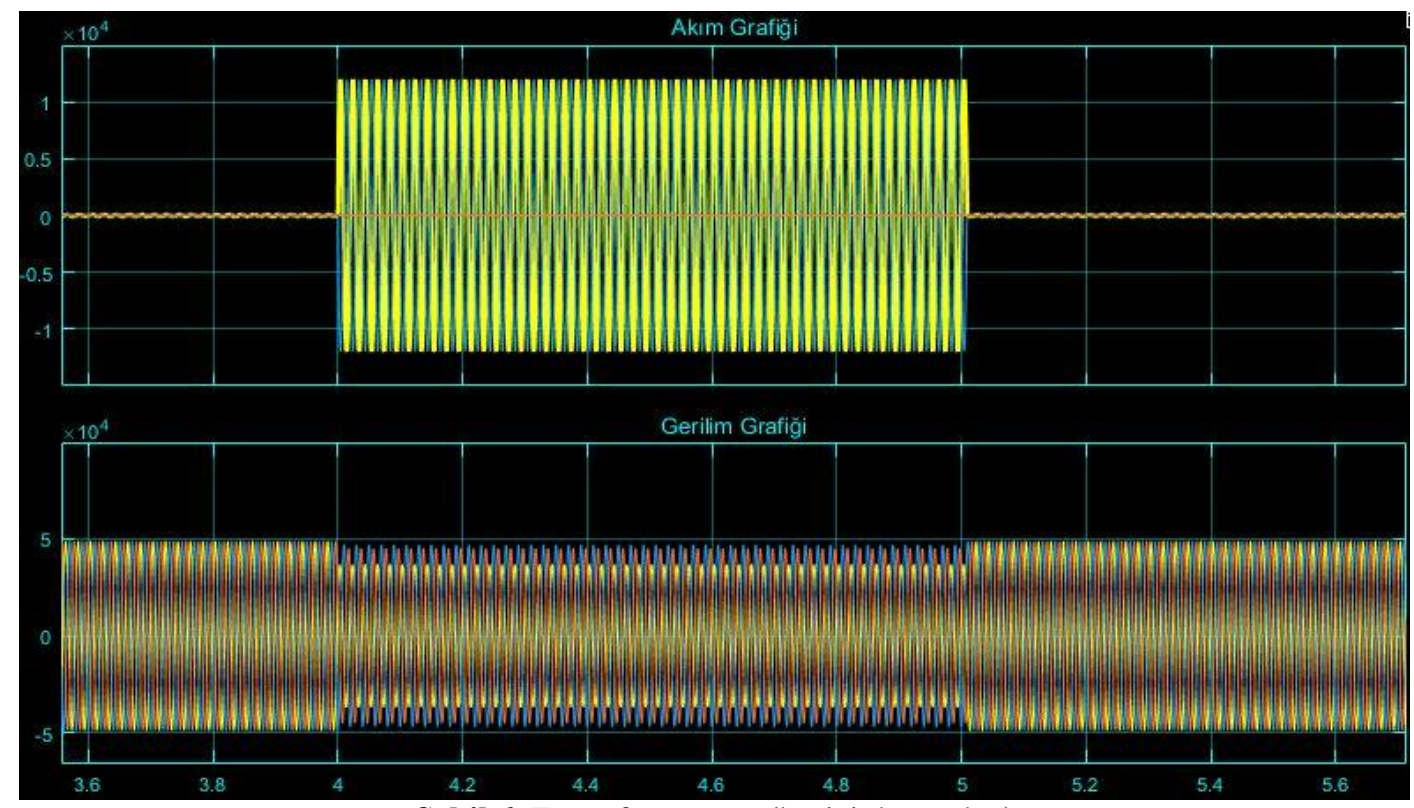

Şekil 6. Faz - faz arızası (kesici devre dışı)

Faz - faz arızası meydana geldiğinde kesicinin devre dışı olduğu senaryoda; devre elemanları üzerinden nominal yük akımı olan 54 A seviyelerinde akım akmakta iken, arızanın meydana gelmesi ile arıza süresi boyunca yaklaşık 1.5 kA (nominal akımın 28 katı) seviyelerinde arıza akımı geçtiği görülmektedir. Dikkat edilecek olursa, faz - toprak arızasında sadece A fazında aşırı akım meydana gelmişken, faz - faz arızasında A ve B fazlarında ani aşırı akım meydana gelmiştir. Gerilimde ise faz - toprak arızasına göre daha fazla ani değişimler meydana geldiği gözlemlenmektedir. 


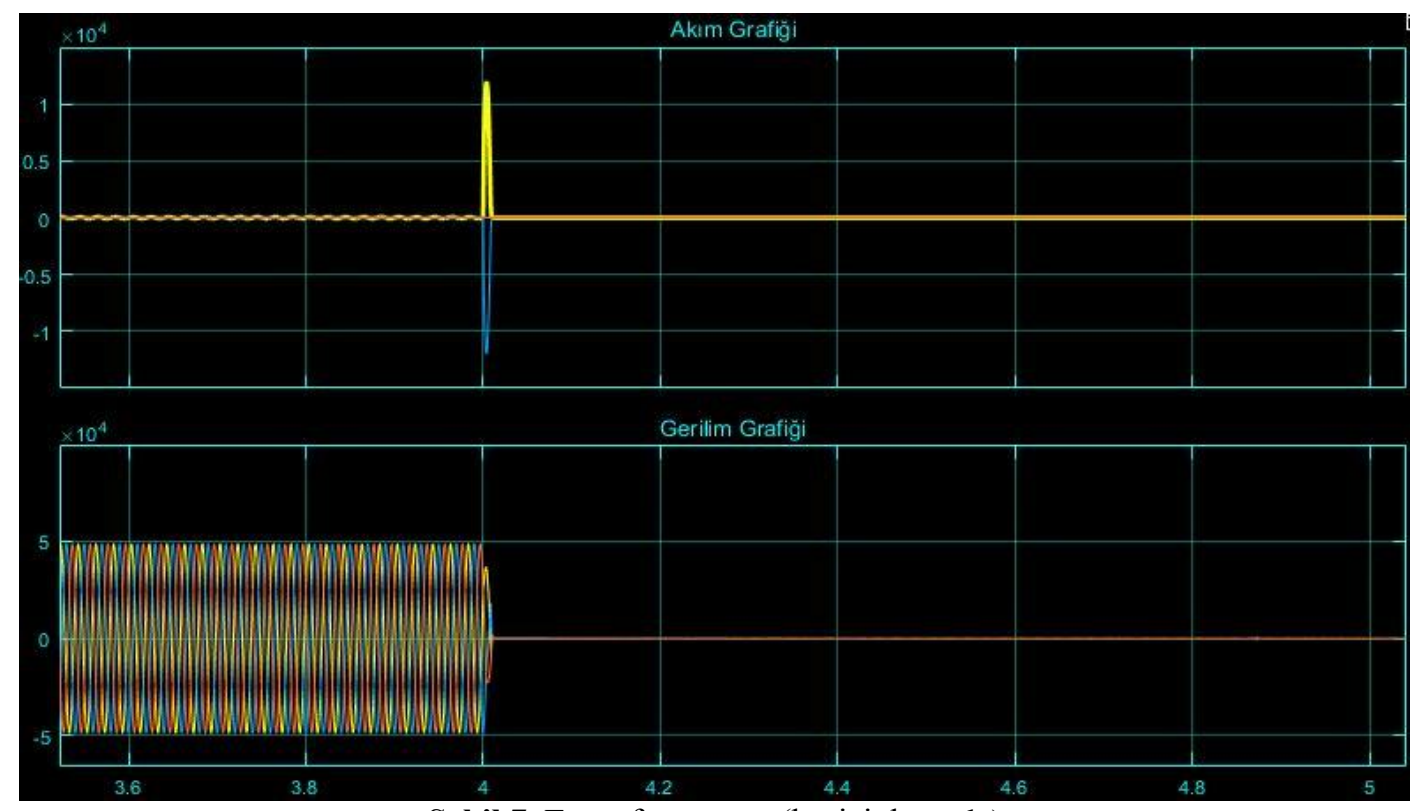

Şekil 7. Faz - faz arızası (kesici devrede)

Faz - faz arızası meydana geldiğinde kesicinin devrede olduğu senaryoda, nominal akım değeri set edilen açma akımı üzerine çıktığı anda kesici devreye girmektedir (Enerji kesilmektedir). Faz - toprak arızasından farklı olarak, kesicinin devreye girmesi ile iki faz üzerinde kesicinin açma süresi kadar akımda ani değişim gözlemlenmektedir.

\subsection{Senaryo 3: Simetrik Üç Faz Arızası Durumu}

Tasarlanan sistemin performansının değerlendirilmesi amacı ile uygulanan senaryolardan üçüncüsü simetrik üç faz arızasıdır. Bu senaryoda üç fazın birbiri ile teması halinde sistemin akım ve gerilim karakteristikleri A ölçüm bloğu üzerinden alınmış olup Şekil 8'de verilmiştir.

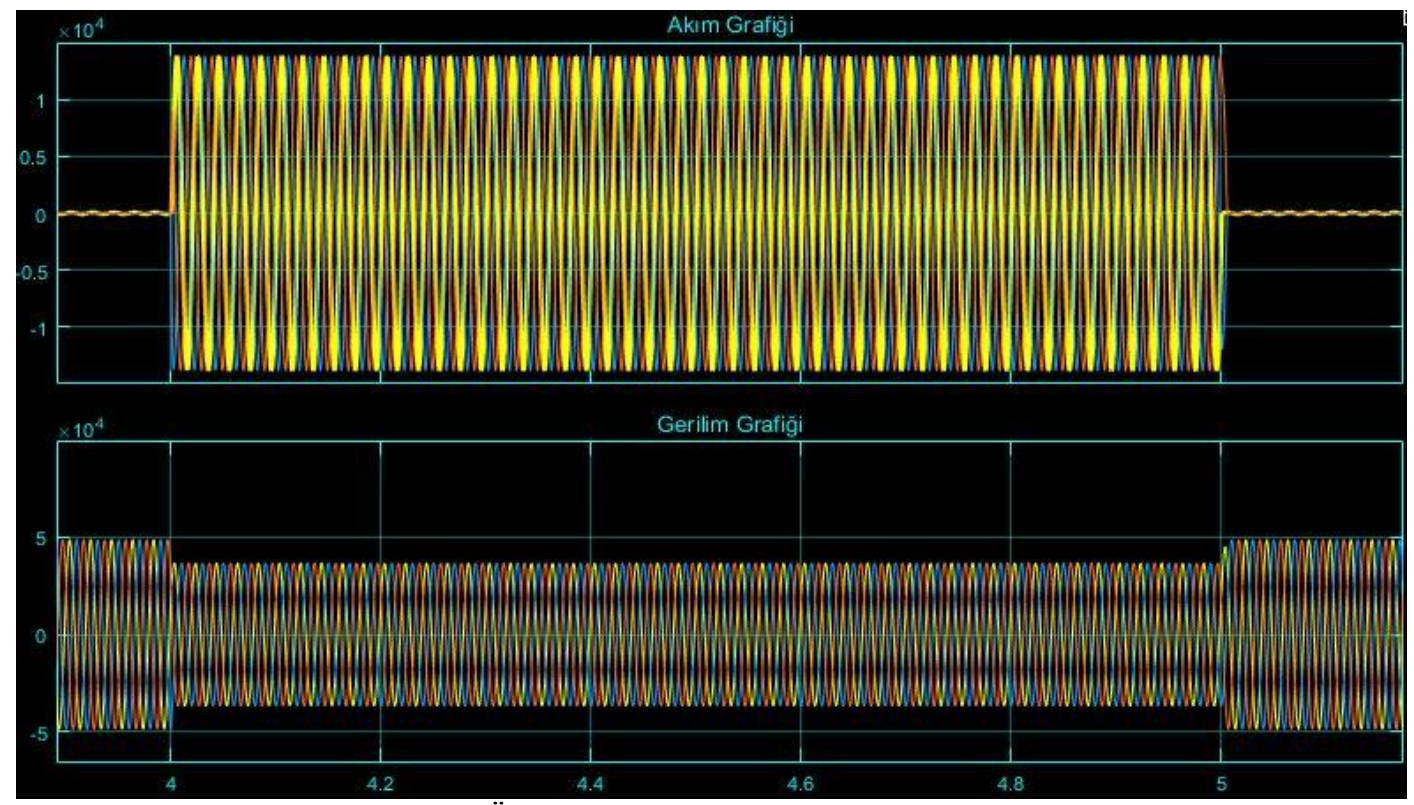

Şekil 8. Üç faz simetrik arızası (kesici devre dışı)

3 faz simetrik arızası meydana geldiğinde kesicinin devre dıșı olduğu senaryoda, diğer arıza durumlarında meydana gelen arıza akım seviyesi gözlemlenmektedir. Diğer arıza türlerinden farklı olarak 3 fazında ani aşırı akım olayına karıştığı, gerilimde ise faz - faz arızasına yakın bir değişim gerçekleştiği grafik üzerinden gözlemlenmektedir. 


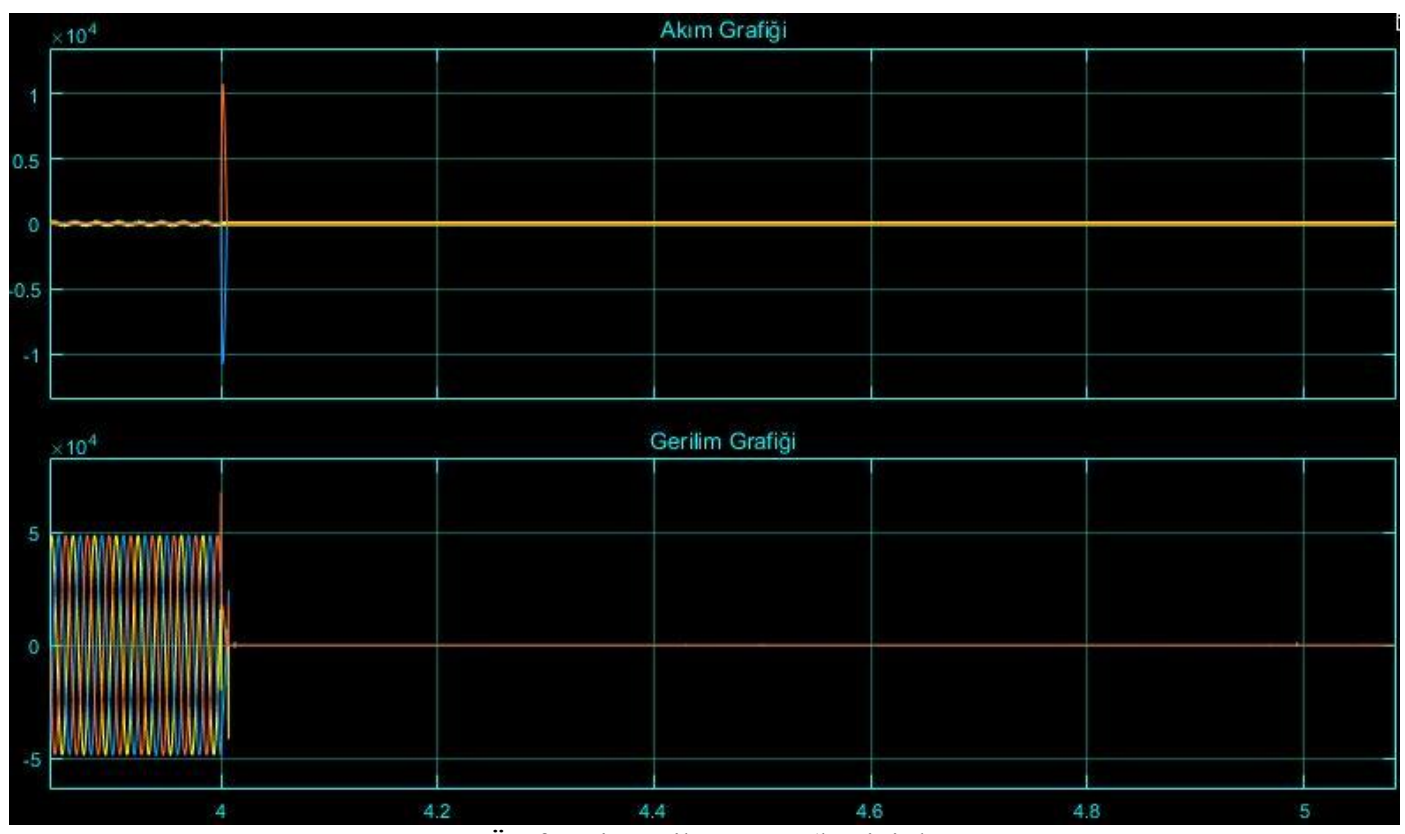

Şekil 9. Üç faz simetrik arızası (kesici devrede)

3 faz simetrik arızası meydana geldiğinde kesicinin devrede olduğu senaryo ile faz - faz arızasında kesicinin devrede olduğu senaryo grafiklerden de görüleceği üzere birbirine çok yakındır.

\section{SONUÇ VE ÖNERILLER}

$\mathrm{Bu}$ çalışmada, güç sistemlerinde meydana gelen arızalara karşı kesici kontrolü sağlanarak, güç sisteminin kararlılığı ve güvenirliğinin arttırılması amaç edinilmiştir.

Tasarlanan SCADA (Supervisory Control and Data Acquisition- Merkezi Denetleme Kontrol ve Veri Toplama), temel yazılım mantığı olan Lojik 0/1 yapısını içermektedir. SCADA (Supervisory Control and Data Acquisition- Merkezi Denetleme Kontrol ve Veri Toplama) operatörü tarafindan butonlardan herhangi birisine müdahale edilmesi durumunda kesici kontrol bloğuna Lojik 1 ifadesi gönderilmektedir. Bu ifade kontrol boğunda değerlendirildikten sonra kesiciye ilgili aç/kapat komutları iletilmektedir. Güç sistemi içerisinde GSM (Global System for Mobile Communications - Mobil İletişim İçin Küresel Sistem) tabanlı RTU (Remote Terminal Unit- Uzak Uç Birimi) cihazları yada modbus gibi haberleşme sistemleri yardımı ile SCADA (Supervisory Control and Data Acquisition- Merkezi Denetleme Kontrol ve Veri Toplama) sistemi devreye alınabilmektedir. Bu yapı ile yüksek gerilim kesicilerine uzaktan müdahale yapılarak saha teknik personelinin güvenliği başta olmak üzere manevraların saniyeler içerisinde yapılması sağlanmaktadır.

Yaşanan asimetrik arızalar ile devre elemanları üzerinden nominal akımdan çok yüksek seviyelerde arıza akımları geçtiği grafikler üzerinden gözlemlenmiştir. Asimetrik arızanın meydana gelmesi ile otomatik kesici milisaniyeler seviyesinde devre enerjisini kesmiştir. Böylelikle devre elemanları üzerinden yüksek arıza akımının geçmesine müsaade edilmemiş ve yaşanabilecek maddi hasarların önüne geçilmiştir. Dolayısı ile bir güç sistemi üzerinde uygun seçim sağlanarak kesici konumlandırılması yapılmalı ve arızanın en kısa sürede maddi hasara yol açmadan sönümlendirilmesi gerekmektedir.

\section{Yazar Katkıları}

Yazarlar çalışmaya eşit oranlı katkı sunmuşlardır.

\section{Çıkar Çatışması}

Makale yazarları aralarında herhangi bir çıkar çatışması olmadığını beyan ederler

\section{KAYNAKÇA}

[1] T. Atalik et al., "Multipurpose platform for power system monitoring and analysis with sample grid applications," IEEE Trans. Instrum. Meas., vol. 63, no. 3, pp. 566-582, 2014.

[2] N. C. Woolley, J. M. Avendaño-Mora, and J. V. Milanović, "Methodology for robust monitoring of
[3] voltage sags based on equipment trip probabilities," Electr. Power Syst. Res., vol. 90, pp. 107-116, 2012.

[4] N. He, W. Kang, P. Ding, and W. Sha, "Research on power system transient stability based on asymmetric fault model," in Proceedings - 2020 International Conference on Urban Engineering and Management Science, ICUEMS 2020, 2020, pp. 225-230. 
[5] O. Yildirim, B. Eristi, H. Eristi, S. Unal, Y. Erol, and Y. Demir, "FPGA-based online power quality monitoring system for electrical distribution network," Meas. J. Int. Meas. Confed., vol. 121, no. May 2017, pp. 109-121, 2018.

[6] Z. Zhang and W. Guo, "Three-phase synchronization adjustment and control of high voltage circuit breaker," in PACIIA 2009 - 2009 2nd Asia-Pacific Conference on Computational Intelligence and Industrial Applications, pp. 88-91, 2009.

[7] M. Njozela, S. Chowdhury, and S. P. Chowdhury, "Impacts of DG on the operation of auto-reclosing devices in a power network," in IEEE Power and Energy Society General Meeting, pp. 1-8, 2011.

[8] M. P. Katti, S. H. Jangamshetti, and A. Rege, "Modeling Of Auto Recloser for Smart Grid," Int. J. Mod. Eng. Res., vol. 2, no. 5, pp. 3172-3177, 2012.

[9] H. Bentarzi, A. Ouadi, and A. Abdelmoumene, "A new framework of smart auto-recloser," in Proceedings - 2018 IEEE 12th International Conference on Compatibility, Power Electronics and Power Engineering, CPE-POWERENG 2018, pp. 1-5, 2018.
[10] A. H. Abdulwahid, "Auto-Recloser Circuit Breaker in Power System Based on Internet of Things for Smart Grid,”2019, vol. 54, no. 3, pp. 234-240.

[11] A. Ayvaz and B. Boylu Ayvaz, "Determination of optimal placement of fault current limiting device against short circuit faults occur in power systems," Sak. Univ. J. Sci., vol. 22, no. 2, pp. 1-1, 2018.

[12] Y. Jiang, M. Huang, Z. G. Zhang, H. Wang, Q. Y. Zheng, and H. P. Liu, "The control of the asymmetric ground fault current of the line," in APAP 2011 - Proceedings: 2011 International Conference on Advanced Power System Automation and Protection, pp. 1452-1457, 2011.

[13] M. C. Taplamacioğlu, S. Uzel, Ö. Aladağ, and S. Keskintaş, "36 kV 1250 A Ön Mekanizmalı Kompakt Vakumlu Devre Kesici Tasarım ve Uygulaması," Nevşehir Bilim ve Teknol. Derg., vol. 8, no. November 2018, pp. 26-32, 2019, 2018.

[14] J. Slavik and Z. Eleschova, "Concept of smart automatic reclosing for transient stability improvement of large power systems," Proc. - 2020 21st Int. Sci. Conf. Electr. Power Eng. EPE 2020, 2020.

[15] A. Ashour, "Modelling of Smart Auto-Recloser with Over Current Protection," Int. J. Eng. Res. Appl., vol. 8, no. 7, pp. 1-5, 2018. 